\title{
Role of Acute Phase Proteins in Pathogenicity of Type 1 Diabetes Mellitus
}

\author{
Shamim SM1*, Manjrekar P2 and D'souza V² \\ 1Department of Biochemistry, College of Medicine, Imam Abdulrahaman Bin Faisal \\ University, Saudi Arabia \\ ${ }^{2}$ Department of Biochemistry, Kasturba Medical College, Mangalore, India
}

*Corresponding author: Shamim Shaikh Mohiuddin, Department of Biochemistry, College of Medicine, Imam Abdulrahaman Bin Faisal University, PO box- 1982, Dammam- 31441, Kingdom of Saudi Arabia, Saudi Arabia, Tel: 00966-562539936; Email: smohiuddin@iau.edu.sa

\section{Abstract}

The role of cytokine mediated acute phase response is observed to be closely involved in the pathogenesis of type 2 diabetes but in case of type 1 diabetes mellitus this role is contradictory. Since in world adolescent population, frequency of developing type 1 diabetes is not negligible, we tested this hypothesis by estimating circulating acute phase proteins in type 1 (T-1) patients. The acute phase proteins named $\alpha 1$ - antitrypsin, $\alpha 1$ - acid glycoprotein; ceruloplasmin and fibrinogen were estimated in the plasma in newly diagnosed $12 \mathrm{~T}-1$. Thirty normal controls to match the age and sex of the test groups were also studied. The levels of these proteins were correlated with their BMI and random plasma glucose values.T-1 cases showed significantly higher levels of the acute phase proteins (except $\alpha 1$ - acid glycoprotein) in comparison to control group. From these findings we can predict a hypothesis that low grade inflammatory process is definitely implicated in the pathogenesis of type1 diabetic patient though results were contradictory in previous studies. This line of pathological basis should be further explored for diagnosis, management and follow up.

Keywords: Type1 Diabetes Mellitus; $\alpha 1$ - Acid Glycoprotein; Ceruloplasmin and Fibrinogen; Insulitis

Abbreviations: HLA: Human Leukocyte Antigen; MHC: Major Histocompatibility Complex; TNF: Tumor Necrosis Factor; GAD: Glutamic Acid Decarboxylase; LEM: Leucocytic Endogenous Mediator; RBS: Random Plasma Glucose; BMI: Body Mass Index

\section{Introduction}

Diabetes Mellitus is a syndrome with disordered metabolism and inappropriate hyperglycemia due to either deficiency of insulin secretion or to a combination of insulin resistance and inadequate insulin secretion to compensate

Type 1 Diabetes Mellitus develops as a result of the synergistic effects of genetic, immunologic and environmental factors that destroy the pancreatic $\beta$-cells. At birth, individuals with genetic susceptibility have normal $\beta$-cell mass which begins to be lost secondary to autoimmune destruction that occurs over months or years. The autoimmune process is thought to be triggered by infection or environmental stimulus and to be 


\section{Diabetes and Obesity International Journal}

sustained by a beta cell specific molecule [1]. In the majority of individuals, immunological markers appear after the triggering event but before diabetes become clinically overt. Due to gradual decline of B cell mass, the insulin secretion is progressively impaired, although normal glucose tolerance is maintained. Features of diabetes do not become evident until a majority of B cells are destroyed $(\sim 80 \%)$. At this point, residual functional beta cell still exists, but insufficient in number to maintain glucose tolerance.

The events that trigger the transition from glucose tolerance to frank diabetes are often associated with increased insulin requirement, as might occurs during infections or puberty. Following the initial clinical presentation of type 1 diabetes mellitus, a "Honeymoon" phase may ensure during which time glycemic control is achieved with modest doses of insulin or rarely insulin is not needed. However, as the autoimmune process destroys the remaining $B$ cells, this fleeting phase of endogenous insulin production from residual beta cells disappears and the individual is completely insulin deficient [2]. The inheritance of human type 1 diabetes mellitus is polygenic. The major susceptibility gene for type 1 diabetes mellitus is located in the human leukocyte antigen region (HLA region) on chromosome 6. This region contains gene that encode the class II major histocompatibility complex (Class II MHC) molecule.

Polymorphisms in the HLA complex appear to account for $40 \%$ to $50 \%$ of genetic risk for developing type 1 diabetes mellitus. Within this region the strongest association is with the DQ locus which is subdivided into alpha and beta loci. Refinement in genotyping of HLA loci have shown that the haplo types DQ A1* 0301, DQ B1* 0302, DQ A1* 501 and DQ B1* 201 have the strongest association with type1 diabetes mellitus [3]. Although analysis of DNA sequence from patients with type 1 diabetes mellitus has not so far shown unique class II sequence, it has been found that susceptibility of type 1 diabetes mellitus is directly related to the amino acid in position 57 of the N-terminal $\beta-1$ domain of the HLA-DQ $\beta$ chain. The specificity and extent of an autoimmune response against pancreatic islets insulin secreting cell are thought to be determined by DQ beta polymorphisms. These polymorphisms are necessary but not in themselves sufficient, for the development of type 1 diabetes mellitus. This implies either the existence of the specific type1 diabetes mellitus related genes or involvement of more than one HLA-D gene controlling the intensity of $\beta$-cell destruction process (which appears to be mediated by cytokines ) or an important role for environmental factors in clinical expression of the disease in genetically susceptible persons [4].
Immune mediated type 1 diabetes mellitus is felt to result from an infection or toxic insult to persons whose immune system is generally predisposed to develop a vigorous autoimmune response either against altered pancreatic $\beta$ cell antigens or against molecule of $\beta$ cell resembling the viral protein. Although other islet cell types are functionally and embryologically similar to $\beta$ cells and express most of the same proteins in $\beta$ cells, they are inexplicably spared from the autoimmune process. Pathologically the pancreatic islets are infiltrated with lymphocytes in a process termed "Insulitis" [5].

The following abnormalities in both the humoral and cellular arms of immune system was identified in type 1 diabetes mellitus

- Islet cell auto antibodies

- Activated lymphocytes in the islets, peripanceatic lymph nodes and systemic circulation.

- Proliferation of T lymphocytes when stimulated by islets protein

- Release of cytokines within the Insulitis

Some cytokines like tumor necrosis factor $\alpha(\mathrm{TNF} \alpha)$, interferon and interleukin 1(IL 1) are seen to be particularly susceptible on $\beta$ cells. The precise mechanism of death of $\beta$ cell involves; formation of nitric oxide metabolites, apoptosis and direct CD8+ T cell cytotoxicity. Pancreatic islets molecule targeted by the autoimmune process including insulin, glutamic acid decarboxylase (GAD), ICA-512/IA-2 (homology with tyrosine phosphate) and phogrin (insulin secretary granular protein). Other less clearly defined autoantigens include an islets gangliosides and carboxypeptidase $\mathrm{H}$. Except insulin, none of the autoantigens are $\beta$ cell specific, which raises the question of how the $\beta$ cells are selectively destroyed? Current theories favor initiation of an autoimmune process directed at one $\beta$ cell molecule which then spreads to other islets molecules as the immune process which destroys $\beta$ cells and creates secondary autoantigens. The $\beta$ cells of individuals who develop type 1 diabetes mellitus do not differ from $\beta$ cells of normal individuals, since transplanted islets are destroyed by a recurrence of the autoimmune process of type 1 diabetes mellitus [2].

Acute phase reaction is a general reaction to inflammation, comparable to the increase in temperature or leukocyte count and is not specific for any given disease. A small protein known as Leucocytic Endogenous Mediator (LEM) which is released from the site of injury probably triggers all these changes. Plasma levels of the individual acute phase proteins rise at different rates. First; the levels of C-reactive protein and $\alpha-1$ antichymotrypsin rise, then within the first $12 \mathrm{hrs}, \alpha-1$ 


\section{Diabetes and Obesity International Journal}

acid glycoprotein followed by $\alpha-1$ antitrypsin, haptoglobin, C4 and fibrinogen levels rise and finally there is a rise of C3 and ceruloplasmin levels. All levels reach their maximum within 2-5 days [6]. These changes which are caused by increased synthesis in the liver donot aid in the diagnosis of the cause of inflammation, but measurement of these proteins with the largest and earliest rises (eg CRP) can be used in monitoring the progress of inflammation or its response to treatment. Increase in synthesis of ARP is accompanied by the decrease in the synthesis of prealbumin, albumin and transferrin (so called negative acute phase reactants), so that only a slight rise in total plasma protein occurs. Therefore the inflammation process causes nonspecific changes in level of individual proteins which may mask changes attributable to a specific disease [7]. This recent explosion of interest in the notion that chronic low grade inflammation and activation of the innate immune system are closely involved in the pathogenesis of type 2 diabetes mellitus was first proposed in 1997-98 [8]. Several studies after that have shown that circulating markers of inflammation, acute phase reactants or interleukin-6 (IL6) are strong predictors of the development of type 2 diabetes [9]. The role of acute phase reactants in the development of type 1 diabetes mellitus is not very clear. $\alpha 1-$ acid glycoprotein, $\alpha-1$ antitrypsin, fibrinogen and ceruloplasmin are few of the acute phase reactants. The level of these inflammatory markers in the pathogenesis of type 1 Diabetes mellitus was of interest.

\section{Materials and Methods}

Patients with features of previously undiagnosed diabetes were examined by the physicians. Of the confirmed cases, patients with a history of chronic inflammatory diseases, episodes of recent acute inflammation, smokers, alcoholics, women on oral contraceptive pills or any other hormones, pregnant women and patients with clinical evidence of neuropathy, nephropathy, and retinopathy were not enrolled in the study. Twelve (12) Type 1 patient of either sex gave their consent to participate in the study. Thirty (30) individuals were chosen from attendants of the patients to serve as controls. All exclusion criteria of the test groups were applied to the control group also. The protocol was approved by the Institutional Ethics Committee. Age, weight and height were recorded and body mass index (BMI) was calculated.

Blood was collected as a random sample before the initiation of therapy in the diabetic patients and the following estimations were carried out:

- Random plasma glucose (RBS): By the glucose oxidase method on Hitachi 917 autoanalyser using Roche Kits.
- Fibrinogen assay [10]: Fibrinogen in plasma was converted to fibrin in the presence of calcium chloride. The fibrin clot was collected and digested with sodium hydroxide. Protein content of the clot was determined by the biuret method.

- Ceruloplasmin assay [11]: At pH 5.4, ceruloplasmin catalysis the oxidation of paraphenylenedia-mine (PPD) to yield a coloured product which is believed to correspond either to Bandrowski's base or to Weuster's red. The rate of formation of the coloured oxidized product is proportional to the concentration of ceruloplasmin, if a correction is made for the nonenzymatic oxidation of PPD. Simultaneous estimations were carried out with and without sodium azide, which inhibits the nonenzymatic oxidation of PPD. The difference between the results of the two assays was proportional to the ceruloplasmin concentration.

- $\alpha-1$ antitrypsin assay [12]: The proteolytic enzyme trypsin hydrolyses casein, with the formation of smaller peptides. The enzyme reaction after suitable interval of time is arrested by the addition of trichloroacetic acid (TCA) which precipitates the proteins, but the peptides are soluble in the acid. The TCA soluble fragments are a measure of proteolytic activity of this enzyme. When the inhibitor is added to the preincubated mixture, it prevents the release of peptides by the proteolytic enzymes. Thus, the estimation of TCA soluble components in the presence and absence of inhibitor is a measure of inhibitory activity against proteolytic enzymes. The TCA soluble fragments were analysed by the method of Lowry, et al. [13]. The final colour formed is a result of the reaction of the peptides with copper ions in alkali and reduction of the phosphomolybdic reagent by the presence of tyrosine and tryptophan present in the treated peptides.

- $\alpha-1$ acid glycoprotein [14]: After removing heat coaguable proteins with perchloric acid, the orosomucoid which remains in the solution was precipitated by phosphotungstic acid and estimated by determining its carbohydrate content by reaction with its tyrosine residues with folin ciocalteau reagent. Statistics The data was analysed by the student's test and the ANOVA test. Pearson's coefficient was applied for correlational analysis.

\section{Statistics}

The data was analyzed by the student's t test and the ANOVA test. Pearson's coefficient was applied for correlation analysis. 


\section{Diabetes and Obesity International Journal}

\section{Results}

The aim of the study was to examine inflammation as a pathogenic cause in type 1 diabetes mellitus cases.

The mean age (range), BMI and the number of males: females are presented in table 1 . The control group participants were so chosen as to cover the age range of the test groups. Table 2 lists the values of random blood sugar (RBS) and acute phase proteins in both groups as mean \pm SD. Test group T- 1 had significant higher values of all the parameters in comparison with the control group. This can be further appreciated in Table 3 which depicts the significance levels ( $p$ values) of the test and control groups.

\begin{tabular}{|c|c|c|}
\hline & Type 1 (n= 12) & Controls (n= 30) \\
\hline Age & $\begin{array}{c}47.27 \pm 7.11(30-60 \\
\text { yrs })\end{array}$ & $\begin{array}{c}43.97 \pm 14.06(30-60 \\
\text { yrs })\end{array}$ \\
\hline BMI & $23.03 \pm 1.46$ & $20.75 \pm 2.27$ \\
\hline $\begin{array}{c}\text { Males : } \\
\text { Females }\end{array}$ & $5: 07$ & $17: 13$ \\
\hline \multicolumn{2}{|c|}{$n=$ number of subjects } \\
\hline
\end{tabular}

Table 1: Patient Characteristics.

\begin{tabular}{|c|c|c|}
\hline Parameters & $\begin{array}{c}\text { Type 1 } \\
\text { Mean } \pm \text { SD }\end{array}$ & $\begin{array}{c}\text { Controls } \\
\text { Mean } \pm \text { SD }\end{array}$ \\
\hline $\begin{array}{c}\text { Random blood Sugar } \\
(\mathrm{mg} / \mathrm{dL})\end{array}$ & $338.25 \pm 50.97$ & $93.20 \pm 7.00$ \\
\hline$\alpha 1$ antitrypsin $(\mathrm{mg} / \mathrm{dL})$ & $495.70 \pm 32.77$ & $349.48 \pm 114.07$ \\
\hline $\begin{array}{c}\alpha 1 \text { acid } \\
\text { glycoprotein }(\mathrm{mg} / \mathrm{dL})\end{array}$ & $94.87 \pm 23.31$ & $102.41 \pm 22.13$ \\
\hline Ceruloplasmin $(\mathrm{mg} / \mathrm{dL})$ & $40.69 \pm 9.85$ & $25.95 \pm 4.10$ \\
\hline Fibrinogen $(\mathrm{mg} / \mathrm{dL})$ & $434.65 \pm 46.36$ & $334.34 \pm 42.19$ \\
\hline
\end{tabular}

Table 2: Levels of the acute phase proteins as Mean \pm SD

\begin{tabular}{|c|c|}
\hline Parameters & T-1 v/s Controls \\
\hline $\begin{array}{c}\text { Random blood sugar } \\
(\mathrm{mg} / \mathrm{dL})\end{array}$ & $<0.0001^{*}$ \\
\hline$\alpha 1$ antitrypsin(mg/dL) & 0.0002 \\
\hline $\begin{array}{c}\alpha 1 \text { acid glycoprotein } \\
(\mathrm{mg} / \mathrm{dL})\end{array}$ & 0.275 \\
\hline Ceruloplasmin(mg/dL) & $<0.0001^{*}$ \\
\hline Fibrinogen(mg/dL) & $<0.0001^{*}$ \\
\hline \multicolumn{2}{|c|}{ T-1= Type 1 newly diagnosed patient } \\
\hline
\end{tabular}

Table 3: Significance (p value)

\section{Discussion}

The aim of this study was to examine inflammation as a pathogenic cause in type 1 diabetes mellitus. In the twelve newly diagnosed type 1 patients, the level of $\alpha 1$ antitrypsin, ceruloplasmin and fibrinogen were found to be significantly increased as compared to control (Table 2). Previous reports on the acute phase reactant levels in Type 1 diabetes are contradictory. Crooke MA et al. has shown that serum sialic acid and acute phase proteins are not elevated in type 1 diabetes [15]. Gomes, et al. [16] reported increased level of CRP, $\alpha 1$-acid glycoprotein and fibrinogen in Type 1 patients. Increased fibrinogen levels, factor VII and whole blood viscosity was also found by John AD Elia, et al. [17]. Similar results are reported by Defeo, et al. [18]. In our study, an increase in $\alpha 1$ antitrypsin, ceruloplasmin and fibrinogen levels were found in type 1 patients. The course of the disease and resulting complications are similar in both type 1 and type 2 diabetes. The most dreaded complication being that of development of atherosclerosis resulting in cardiovascular diseases. Fibrinogen is identified as an independent risk factor in the development of ischemic heart diseases [19].

Irrespective of the patients being type 1 or type 2 , the risk of developing atherosclerosis remain the same. Hence there must be some mechanism which links the pathogenecity of type 1 and type 2 diabetes. Barrazzani R, et al. [20] infused insulin to non diabetics, type 1 and type 2 diabetics and studied its role in fibrinogen production. Insulin replacement activity suppressed fibrinogen production in non diabetics and type 1 diabetic individuals. Fibrinogen production and its plasma concentration increased in insulin resistant type 2 diabetics when euglycemia and euaminoaciduria were maintained. They postulated that an altered response to insulin causes hyperfibrinogenemia in type 2 diabetic patients. If this hypothesis holds well, it doesn't explain hyperfibrinogenemia in type 1 diabetics where the basic pathology is insulin deficiency. Hence there must be some other factors which stimulate increased fibrinogen synthesis in type 1 patients contributing to cardiovascular disease risk. An insulin resistance syndrome score [21] was developed based on clinical risk factor in patient with type 1 diabetes and validated using euglycemichyperinsulinemic clamp studies. Fibrinogen levels were significantly associated with this insulin resistance syndrome score. This may explain high fibrinogen level in type 1 diabetes. But it still does not answer the above findings since the type subjects in this study were newly diagnosed. Hence the mechanism of increased fibrinogen synthesis needs to be proved further. Ceruloplasmin is known to have antioxidant action [22]. It is also an acute phase protein with a response of intermediate magnitude. Ceruloplasmin is known to stimulate cell proliferation and angiogenesis [23]. The higher levels of ceruloplasmin in 


\section{Diabetes and Obesity International Journal}

type 1 as compared to controls may be due to an oxidative stress that is prevalent type 1 diabetes [24,25].

Eduardo Ehrenwald [26] showed a very interesting feature of ceruloplasmin. The intact human ceruloplasmin which is $132 \mathrm{KD}$ molecules caused increased oxidation of LDL in vitro. Starkebaum G and Harlan JM, et al. also showed that increased serum ceruloplasmin could generate excess oxidized LDL, and cause vascular injury by generating free radicals such as hydrogen peroxide [27]. These findings defined the earlier notions of the antioxidant activity of ceruloplasmin. By further investigations Eduardo Ehrenwald, et al. found that the holoceruloplasmin, which is seen in serum as a $132 \mathrm{KD}$ molecule, has a prooxidant effect and the action was attributed to the copper ions present in ceruloplasmin. The commercially available ceruloplasmin is a degraded product containing either $115 \mathrm{KD}$ fragment or $19 \mathrm{KD}$ fragment or both. These had an antioxidant effect. The works done to show that ceruloplasmin as an antioxidant used these degraded products. The antioxidant action of a commercial ceruloplasmin was observed even in the system where holoceruloplasmin oxidized LDL [26]. Hence considering ceruloplasmin as an antioxidant in vivo is debatable. The LDL oxidizing action of ceruloplasmin could probably explain at least in part of the increased risk of IHD in type 1 diabetes (as well as in type 2 diabetics also).

The underlying mechanism for the augmented acute phase response is not well understood and the stimulus for the response is unknown. A number of hypotheses have been put forward and these include insulin resistance, obesity, atherosclerosis, other diabetic complications and maladaptation of the normal innate immune response to environmental threats [28-30]. The most widely studied is the association of obesity, insulin resistance, type 2 diabetes and acute phase reactants. It has been shown that adipocytes secret a number of proinflammatory cytokines in the postprandial state [3133]. The term 'diabecity' has received attention [34] of late for obese diabetics. The 'common soil' theory proposed, evaluates the involvement of inflammation in the pathogenesis of diabetes and atherosclerosis. Hyperglycemia and insulin resistance could promote inflammation and inflammation may be a factor linking diabetes mellitus to the development of atherosclerosis. Elevated glucose levels promote inflammation by increasing oxidative stress [35], by the formation of AGEs and increased TNF (kappa B) [36]. In this study, the mean BMI was found to be $19.5 \pm 1.23$ in type 1 patient and $24.03 \pm 1.46$ in type 2 patients. No correlation was found between BMI and acute phase reactants. Hence it can be summarized that there could be multiple pathways involved in the activation of the innate immunity system and much work needed to be done to establish either a casual role in the development of mainly type 2 diabetes and could be type 1 diabetes also.

\section{References}

1. Pugliese A (1995) Unraveling the genetics of insulin dependent type I diabetes: The search must go on. Diabetes Rev 7(1): 39-54.

2. Fausi AS, Braunwald E, Isselbacher KJ, Wilson JD, Joseph BM, et al. Endocrinology and metabolism, Diabetes Mellitus. In: Harrison's Principle of Internal Medicine.

3. Lowe WL (1998) Genetics of diabetes. In: Principles of Molecular Medicine, JL Jameson (Eds.), Humana NJ, Totowa, pp: 433-442.

4. Schranz DB, Lernmack A (1998) Immunology in diabetes, an update. Diabetes Metab Rev 14(1): 3-29.

5. Christopher RW Edwards, Ian AD Boucher, Christopher H, Edwin C (1995) Endocrine and Metabolic Diseases; Diabetes Mellitus. In: Davidson's Principles and Practice of Medicine. 17th (Edn.), ELBS, pp: 725.

6. Murray RK, Granner DK, Mayers PA, Roadwell VW (2002) Plasma proteins, immunoglobulin and blood coagulation. In: Harper's Biochemistry. 25 th $(E d n$.$) ,$ McGraw Hill, pp: 740.

7. Tietz NW (1986) Amino acids and proteins. In: Textbook of clinical chemistry. WB Saunders Company, pp: 519-618.

8. Spranger J, Kroke A, Mohlig M, Huffman K, Bergman MM, et al. (2003) Inflammatory cytokines and the risk to develop type 2 diabetes: results of the prospective population based European Prospective Investigation Cancer and Nutrition (EPICN)- Potsdam study. Diabetes 52(3): 812-817.

9. Snijder MB, Dekker JM, Visser M, Stehouwer CDA, Van Hinsberg VWM, et al. (2001) C-reactive protein and diabetes type 2. Diabetologia 44 (S1): 115A.

10. Varley H, Gowenlock AH, Bell M (1991) Determination of plasma fibrinogen. In: Practical Clincial Biochemistry. $5^{\text {th }}$ (Edn.), CBS publishers and distributors, India, pp: 557-1559.

11. Sunderman FW, Nomoto S (1970) Measurement of human serum ceruloplasmin by its p- 


\section{Diabetes and Obesity International Journal}

phenylenediamine oxi-dase activity. Clinical Chemistry 16(11): 903-909.

12. Sundaresh CS, Aroor AR, Pattabiraman TN (1978) Compara-tive study of amidolytic and caseinolytic methods for the determination of urinary trypsin inhibitor. Indian J Med Res 68: 341-334.

13. Loway OH, Rosebaugh NJ, Farr AL, Randall RJ (1951) Pro-tein measurement with folin phenol reagent. J Biol Chem 193(1): 265-275.

14. Winzler RJ (1955) Determination of serum $\alpha-1$ acid gly-coprotein. In: Methods in Biochemical Analysis. Inter-science Pub, New York, 2: 270.

15. Mohamed Ali V, Goodrick S, Rawesh A, Mile JM, Katz DR, et al. (1997) Human subcutaneous adipose tissue releases IL- 6 but not TNF- $\alpha$ in vivo. J Clin Endocrinol Metab 82(12): 4196-4200.

16. Gomes MB, Piccirilo LJ, Nogueira VG, Matos HJ (2003) Acute phase proteins among patients with type1 diabetes. Diabetes Metab 29(4): 405-411.

17. Elia JAD, Weinrauch LA, Gleason RE, Lipinska I (2001) Fibrinogen and factor VII levels improve with glycemic control in patients with type 1 diabetes mellitus who have microvascular complication. Arch Int Med 161(1): 98-101.

18. Defeo P, Volpi E, Lucidi P, Cruciani G, Reboldi G, et al. (1993) Physiological increments in plasma insulin concentration have selective and different effects on synthesis of hepatic proteins in normal humans. Diabetes 42(7): 995-1002.

19. ErnstE, Resch KL (1993) Fibrinogen as a cardiovascular risk factor: A met analysis and review of the of the literature. Annals of Internal Medicine 118(12): 956-963.

20. Barrazzani R, Kiwanuka E, Zanneti M, Cristini M (2003) Insulin acutely increases fibrinogen production in individuals with type 2 diabetes but not in individuals without diabetes. Diabetes 52(7): 18511856.

21. Williams KV, Erbey JR, Becker D, Arslanian S, Ochad TJ (2000) Can clinical factors estimate insulin resistance in Type 1 diabetes. Diabetes 49(4): 626632.

22. Goldstein IM, Kaplan HB, Edelson HS, Weissmann G (1979) Ceruloplasmin, A scavenger of Superoxide anion radicals. J Biol Chem 254(10): 4040-4045.
23. Allessandri G, Raju K, Gullino PM (1983) Mobilization of capillary endothelium in vitro induced by effectors of angiogenesis in vivo. Cancer Res 43(4): 1790-1797.

24. Telci A, Cakatay U, Salman S, Satman I, Sivus A (2000) Oxidative protein damage in early stage type 1 diabetic patients. Diabetes Res clin Prac 50(3): 212223.

25. Baynes JW (1991) Role of oxidative stress in development of complications of diabetes. Diabetes 40(4): 405-412.

26. Ehrenwald E, Chisoim GM, Fox PL (1994) Intact human ceruloplasmin oxidatively modifies low density lipoprotein. J Clin Invest 93(4): 1493-1501.

27. Starkebaum G, Harlan JM (1986) Endothelial cell injury due to copper catalyzed hydrogen peroxide generation from Homocysteine. J Clin Invest 77(4): 1370-1376.

28. Pickup JC, Crooke MA (1998) Is type 2 diabetes mellitus a disease of the innate immune system? Diabetologia 41(10): 1241-1248.

29. Grimble RF (2002) Inflammatory status and insulin resistance. Curr Opin Clin Nutr Metab 5(5): 551-559.

30. Pradhan AD, Ridkar PM (2002) Do atherosclerosis and type 2 diabetes share a common inflammatory basis? Eur Heart J 23(11): 831-834.

31. Mohammed Ali V, Goodrick S, Rawesh A, Katz DR, Miles JM, et al. (1997) Subcutaneous adipose tissue releases interleukin-6, but not tumor necrosis factor $\alpha$, in vivo. J Clin Endocrinol Metab 82(12): 4196-4200.

32. Hotamisligil GS, Amer P, Cam JF, Atkinson RL, Spiegelman BM (1998) Increased adipose tissue expression of tumor necrosis factor $\alpha$ in human obesity and insulin resistance. J Clin Invest 95(5): 2409-2415.

33. Fried SK, Budkin DA, Greenberg AS (1998) Omental and subcutaneous adipose tissues of obese subjects release interleukin-6: adipose tissue difference and regulation by glucocorticoids. J Clin Endocrinol Metab 83(3): 847-850.

34. Duncan BB, Schmidt MI, Pankow JS, Ballantyne CM, Couper D, et al. (2003) Low grade inflammation and development of type2 diabetes: The Atherosclerosis Risk in Communities study. Diabetes 52(7): 17991805. 


\section{Diabetes and Obesity International Journal}

35. Bayens JW, Thorpe SR (1999) Role of oxidative stress in diabetic complications: a new perspective on an old paradigm. Diabetes 48(1): 1-9.
36. Brownlee M (2001) Biochemistry and molecular cell biology of diabetic complication. Nature 414(6865): 813-820. 